\title{
A TECHNIQUE FOR ESTIMATION OF BARN OWL (TYTO ALBA STERTENS Hartert, 1929) PREY BIOMASS WITH SPECIAL REFERENCE TO MANDIBLE LENGTH-BODY WEIGHT RATIO OF SMALL MAMMALS
}

\section{P. Neelanarayanan}

P.G. and Research Department of Zoology, Nehru Memorial College (Autonomous), Puthanampatti, Tiruchirappalli, Tamil Nadu 621007, India Email: pnn31@hotmail.com ; pnn31@yahoo.co.in

\begin{abstract}
An investigation was made to study the relationship between mandible length and body weight in six species of small mammals, which are the chief prey base of the Barn Owl Tyto alba. Regression equations for four species of rodent pests, $B$. bengalensis, M. meltada, T. indica and R. rattus are given for the quantification of prey biomass by using mandible length as a function of body weight. The prey biomass for $S$. murinus (40g) and $M$. booduga $(12 \mathrm{~g})$ can be estimated by using mean body weight values.
\end{abstract}

\section{KEYwORDS}

Barn Owl, Bandicota bengalensis, body weight, mandible length, Millardia meltada, Mus booduga, prey biomass, Rattus rattus, small mammals, Suncus murinus, Tatera indica, Tyto alba

Owls are in general highly beneficial birds of prey to mankind since they are rodent hunters. They hunt rodents at night and help to keep in check the populations of these mammals. Among the owls, Barn Owls have global distribution matched by few other species in the world (Burton, 1984; Taylor, 1994), with 36 subspecies distributed throughout the world (Taylor, 1994). In the Indian subcontinent there are two known subspecies, Tyto alba stertens in peninsular India and Tyto alba de-roepstroffi, a rare subspecies restricted to the southern Andaman Islands of the Indian Ocean (Bunn et al., 1982; Ali \& Ripley, 1983; Taylor, 1994).

The literature reviews on major diet of barn owls from six continents were reported to be rodents, the most important small mammalian group. Out of 52 key studies, analysed on Barn Owl's diet by Taylor (1994), the rodents constituted more than $50 \%$ of all prey items in 47 studies and they formed more than $75 \%$ of all prey items by number in 33 studies, suggesting thereby that Barn Owls are excellent rodent hunters in nature.

The results of average daily food requirements of Barn Owls under wild conditions have shown that in two studies, they required more than $75 \mathrm{~g}$ prey/day (Taylor, 1994; Kanakasabai et al., 1998); and in one study (Kanakasabai et al., 1998 ) their requirements were more than $100 \mathrm{~g} /$ day, indicating that Barn Owls are potential rodent eaters in nature.

The predatory pressure of Barn Owls over different prey spectrum was studied by an indirect method, namely, the regurgitated pellet analysis, which is a reliable technique than other techniques as far as owls are concerned (Errington, 1932; Glading et al., 1943) and particularly for Barn Owls (Marti, 1987). The $\mathrm{pH}$ of the Barn Owl's stomach is higher (less acidic) than that of many other predatory birds and hence most of the bones of ingested prey are left undigested (Smith \& Richmond, 1972). Further, the skulls and mandibles of even the most delicate small mammal and bird prey are found intact in the pellets and can easily be identified (Taylor, 1994).

According to Marti (1987), both prey frequency and biomass quantification methods are equally valuable because the former provides better information on the relative impact of a raptor upon various prey species, while the latter may give a more accurate evaluation of the relative importance of different prey species in the diet.

The prey biomass quantification involves two methods. The first method is to utilize the mean body weight of respective prey species (Marti, 1987). Quantification of prey biomass by using standard log-log regression equations of right/left mandible length as a function of body weight (Hamilton, 1980) is the second method. It is understood from the review of literature that there is no published information on quantification of prey biomass by using mandible length as a function of body weight and hence the present study was conducted with the following objective, i.e., to study the relationship between mandible length and body weight in six species of small mammals.

\section{Materials AND Methods}

Six adult and six sub-adult Barn Owls (approximately 812 months old) were captured from the temple towers of Mayiladuthurai $\left(11^{\circ} 2^{\prime} \mathrm{N}-79^{\circ} 49^{\prime} \mathrm{E}\right)$ Tamil Nadu, India. They were brought to the aviary and were kept in individual cages. The size of each cage was $3 \mathrm{ft} \times 3 \mathrm{ft} \times 3 \frac{1}{2} \mathrm{ft}$. Adequate care was taken to have smooth surface on both inside and outside the cages in order to avoid any physical injury to the caged animals. Of the birds, four healthy adults (mean $=382.50 \mathrm{~g}$; range $=$ $375-390 \mathrm{~g})$ and four normal sub-adults $(\overline{\mathrm{X}}=413.75 \mathrm{~g}$; range $=$ $410-420 g$ ) were employed for this study.

In previous studies, the diet of Barn Owl comprising of small mammals were to the tune of $98.18 \%$ (Neelanarayanan et al., 1995) and 90.5\% (Santhanakrishnan, 1995) prompting me to study Bandicota bengalensis, Millardia meltada, Mus booduga, Tatera indica, Rattus rattus and Suncus murinus as small mammal representatives for prey biomass estimation by using the mandible or lower jaw or dentary bone as a function of body weight. The rodents/insectivore were provided to the four individually caged adult Barn Owls with a body weight of $10 \mathrm{~g}$-interval ranging from $10 \mathrm{~g}$ to $200 \mathrm{~g}$ for B. bengalensis; $10 \mathrm{~g}$ to $90 \mathrm{~g}$ for M. meltada, $10 \mathrm{~g}$ to $180 \mathrm{~g}$ for T. indica; $10 \mathrm{~g}$ to $180 \mathrm{~g}$ for R. rattus; and $10 \mathrm{~g}$ to $60 \mathrm{~g}$ for S. murinus. As for M. booduga $10 \mathrm{~g}$ and $15 \mathrm{~g}$ animals were given to the caged Barn Owls. For every $10 \mathrm{~g}$ weight category of each species, a minimum of three and up to a maximum of six rodents were used. The mean length

Manuscript 1569; (C) ZOO; Date of publication 21 December 2006 Received 24 May 2006; Finally accepted 08 December 2006 
values of mandibles were taken for representing each $10 \mathrm{~g}$ weight category. The following day the regurgitated pellets were collected, oven dried, labelled (species and weight of the prey given with date) and bagged. They were analysed individually by using $8 \% \mathrm{NaOH}$ as suggested by Neelanarayanan et al. (1998) for obtaining the mandibles. The mandibular length was measured between incisor socket and condyle / angular process using a vernier caliper with $0.1 \mathrm{~mm}$ accuracy. The regression of body weight (Y) on mandible length ( $\mathrm{x}$ ) was calculated separately for six species of small mammals as suggested by Morris (1979).

\section{Results AND Discussion}

\section{Mandible length and prey weight relationship}

The regression lines of four species of small mammals viz., B. bengalensis, M. meltada, T. indica and $R$. rattus showed a linear relationship between the two variables viz., mandible length and prey body weight. This can be noticed from Figs. 1-4 that the points are close to the line indicating a close relationship between mandible length and prey body weight.

The regression equations for mandible length and prey body weight of four species of small mammals are:

B. bengalensis

$\mathrm{Y}=-320.81+184.37 \times 17.3(\mathrm{r}=0.97 ; \mathrm{n}=81 ;$ range $=17.1-27.7 \mathrm{~mm})$

M. meltada

$\mathrm{Y}=-171.56+130.57 \times 14.0(\mathrm{r}=0.96 ; \mathrm{n}=39 ;$ range $=13.6-19.5 \mathrm{~mm})$

T. indica

$\mathrm{Y}=-248.65+163.77 \times 14.0(\mathrm{r}=0.98 ; \mathrm{n}=57 ;$ range $=13.8-25.3 \mathrm{~mm})$

R. rattus

$\mathrm{Y}=-277.32+181.18 \times 15.7(\mathrm{r}=0.97 ; \mathrm{n}=55 ;$ range $=15.6-24.6 \mathrm{~mm})$

It is evident from Figs. 5 and 6 that the regression lines of S. murinus and M. booduga did not show a linear relationship between mandible length and prey body weight. The regression equations for these species are:

S. murinus

$\mathrm{Y}=30.43+1.70 \times 16.7(\mathrm{r}=0.13 ; \mathrm{n}=23 ;$ range $=16.5-19.0 \mathrm{~mm})$

M. booduga

$\mathrm{Y}=-16.47+28.23 \times 10.3(\mathrm{r}=0.48 ; \mathrm{n}=16 ;$ range $=10.3-11.4 \mathrm{~mm})$.

Morris (1979) reported such relationship between lower jaw length and body weight in the Brown Rat, Rattus norvegicus. The above cited regression equations for B. bengalensis, $M$. meltada, T. indica and $R$. rattus can be utilized for prey biomass estimation. The prey biomass for S. murinus $(40 \mathrm{~g})$ and $M$. booduga $(12 \mathrm{~g})$ can be estimated by using mean body weight values given by Kanakasabai et al. (1998).

\section{REFERENCES}

Ali, S. \& S.D. Ripley (1983). Hand Book of Birds of India and Pakistan. Oxford University Press, London.

Bunn, D.S., A.B. Warburton \& R.D.S. Wilson (1982). The Barn Owl. Buteo Books. Vermillion, S.D., 264pp.

Burton, J.A. (ed.) (1984). Owls of The World. Tanager Books, Dover, New Hampshire, 208pp.

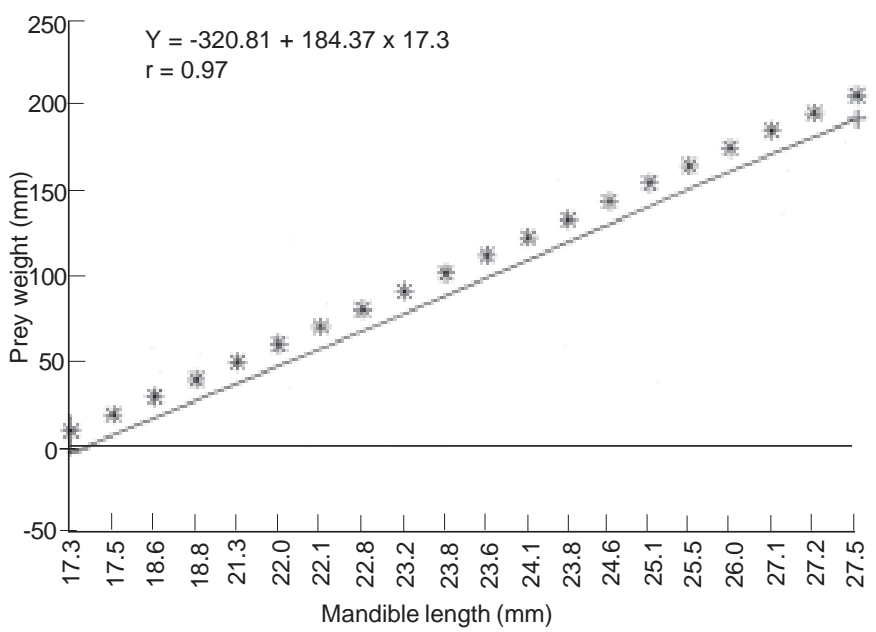

Figure 1. Regression of Bandicota bengalensis body weight on mandible length

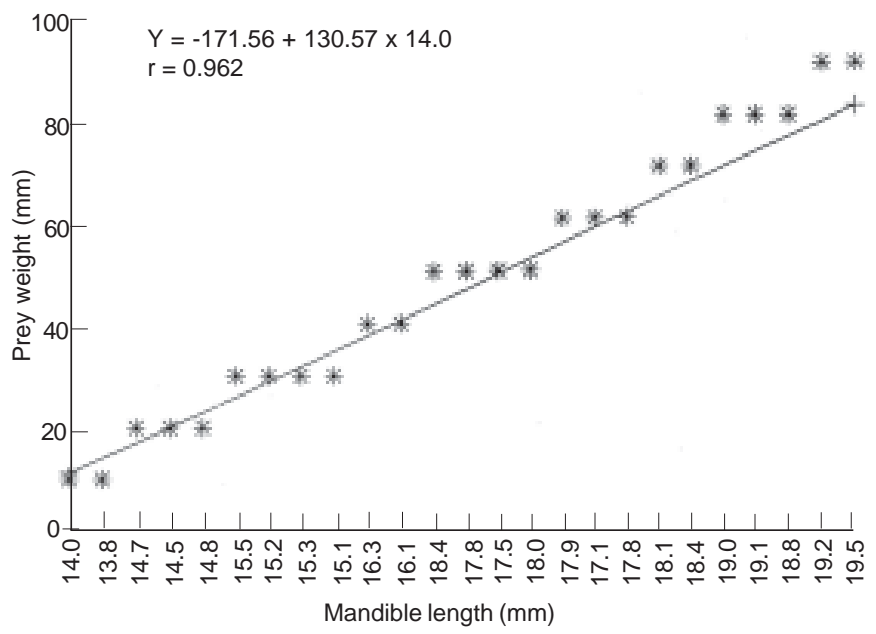

Figure 2. Regression of Millardia meltada body weight on mandible length

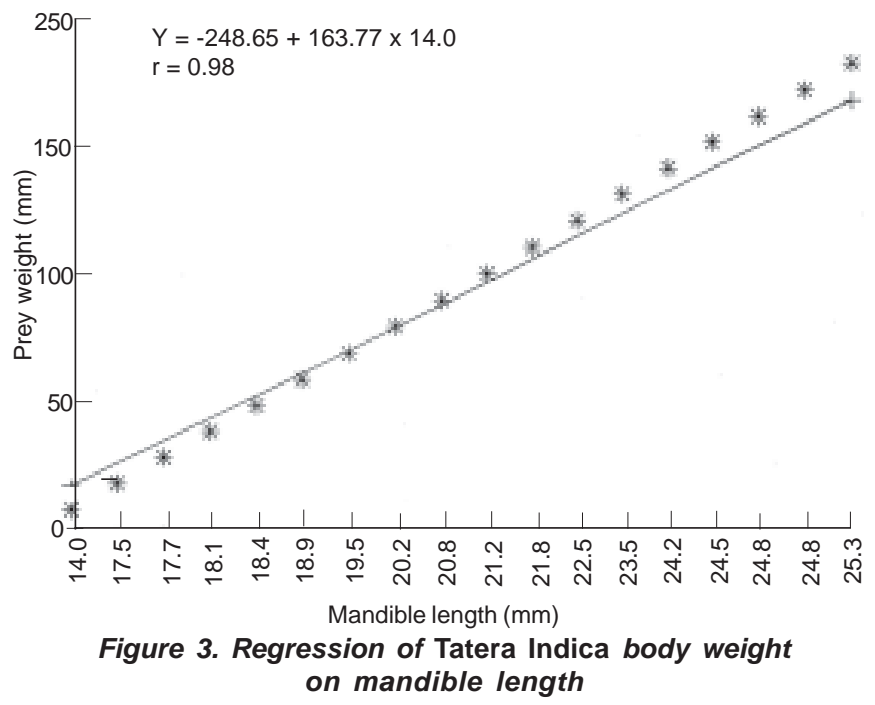



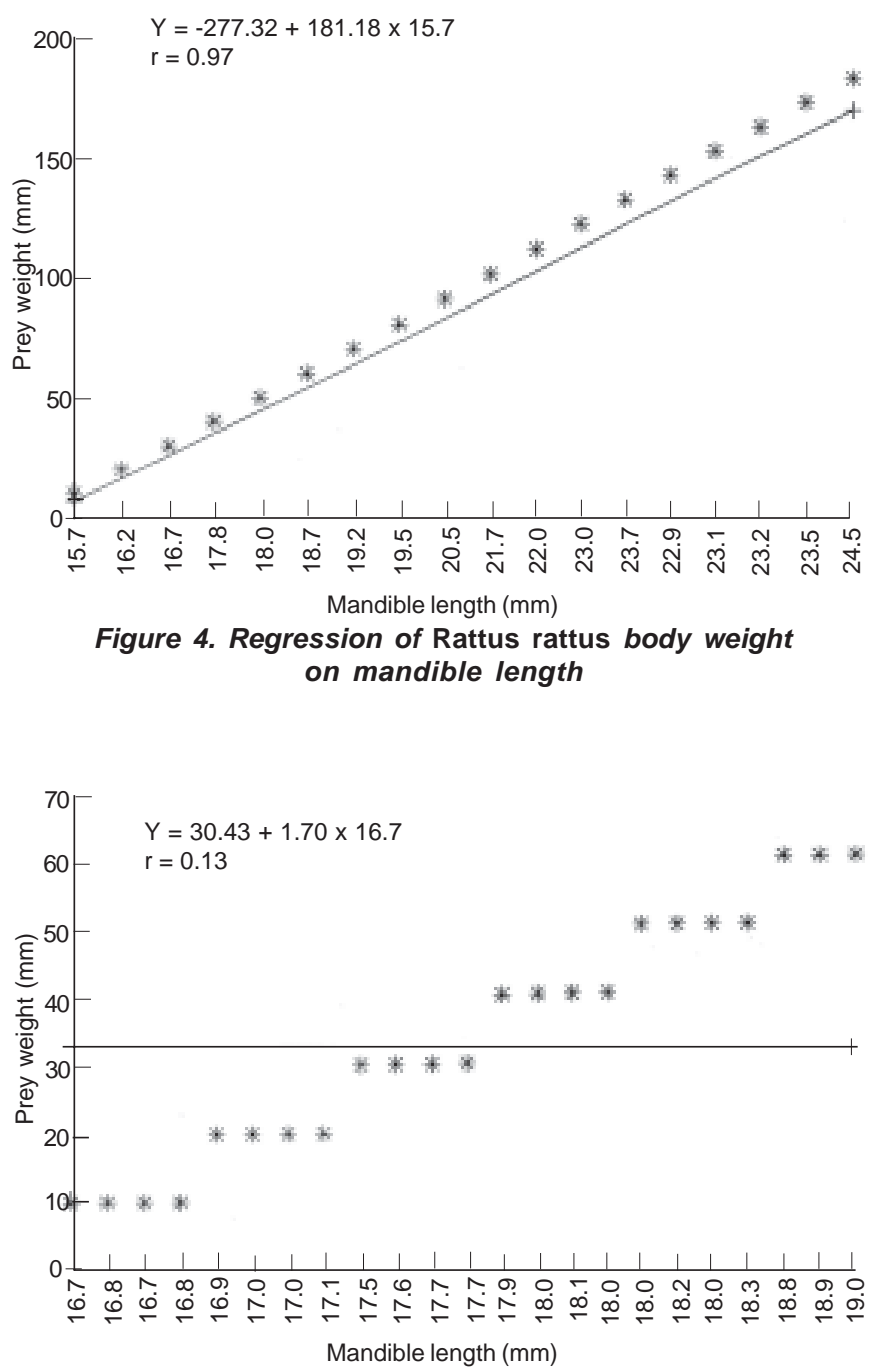

Figure 5. Regression of Suncus murinus body weight on mandible length

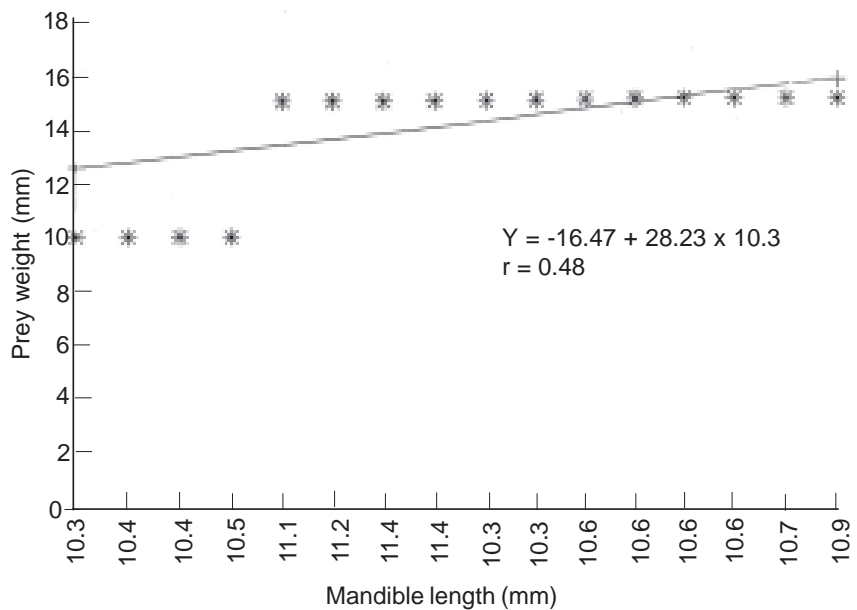

Figure 6. Regression of Mus booduga body weight on mandible length
Errington, P.L. (1932). Technique of raptor food habit study. Condor 34: 7586 .

Glading, B., D.F. Tillotson \& D.M. Selleck (1943). Raptor pellets as indicators of food habits. California Fish and Game 29: 92-121.

Hamilton, K.L. (1980). A technique for estimating Barn Owl prey biomass. Raptor Research 14(2): 52-55.

Kanakasabai, R., P. Neelanarayanan \& R. Nagarajan (1998). Quantifying Barn Owl (Tyto alba stertens) prey frequency and biomass. Proceedings of the First National Symposium on Birds in Agricultural Ecosystem, A.N.G.R. Agricultural University, Hyderabad, 153-157pp.

Marti, C.D. (1987). Raptor food habit studies, pp.67-79. In: Pendleton, B.G., B.A. Millsap, K.W. Kline \& D.A. Bird (eds.). Raptor Management Techniques Manual. National Wildlife Federation Science \& Technology Series No. 10, Washington, D.C.

Morris, P. (1979). Rats in the diet of the Barn Owl (Tyto alba). Journal of the Zoological Society of London 189: 540-545.

Neelanarayanan, P., R. Nagarajan \& R. Kanakasabai (1995). The Common Barn Owl, Tyto alba: A potential predator of rodent pests. Pestology 19(9): 34-37.

Neelanarayanan, P., R. Nagarajan \& R. Kanakasabai (1998). Studying diet of Barn Owl (Tyto alba stertens) by pellet analysis. Proceedings of the First National Symposium on Birds in Agricultural Ecosystem, A.N.G.R. Agricultural University, Hyderabad, 125-131pp.

Santhanakrishnan, R. (1995). Ecology of Barn Owl, Tyto alba (Scopoli) with special reference to its population, Feeding and Breeding in Mayiladuthurai, Tamil Nadu, South India. Ph.D. Dissertation, Bharathidasan University, Tiruchirappalli, South India (Unpublished). Smith, C.R. \& M.E. Richmond (1972). Factors affecting pellet egestion and gastric $\mathrm{pH}$ in the Barn Owl. Wilson Bulletin 84: 179-186.

Taylor, I.R. (1994). Barn Owls: Predator prey relationships and conservation. Cambridge University Press, Cambridge, 303pp.

\section{ACKNOWLEDGEMENTS}

The financial assistance rendered by ICAR, New Delhi for carrying out this research work is gratefully acknowledged. I am highly indebted to Dr. R. Kanakasabai for his valuable guidance during the study. I thank the Principal and the Management of A.V.C. College for their help and encouragement. I thank profusely Mr. S. Marimuthu of Natham Village, Mayiladuthurai and his team for prompt and continuous supply of field rodents. The moral support and encouragement extended by Prof. M. Ponnambalam, Secretary, Dr. S. Ramalingam, Principal and Prof. K. Kanagasundari, H.O.D. of Zoology, Nehru Memorial College, Puthanampatti are gratefully acknowledged.

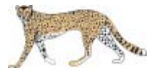

